\title{
La alegría de ser un entrenador de circuito está en los ojos del espectador
}

\author{
Janet Young
}

\section{RESUMEN}

Este trabajo destaca los roles del entrenador de circuito y las características principales de la 'vida en el circuito'. Además, demuestra que diferentes mentalidades sustentan experiencias positivas y negativas como entrenador de circuito, y ofrece sugerencias para facilitar y mejorar las positivas. Estas experiencias son muy significativas dado el impacto que ejercen sobre el bienestar del entrenador, su satisfacción y rendimiento laboral (Gallwey, 2009).
Palabras clave: viajar, giras, entrenar, mentalidad

Recibido: 12 Diciembre 2017

Aceptado: 6 Enero 2018

Autor correspondiente:

Janet Young.

Correo electrónico:

janet young7@yahoo.com.au

\section{INTRODUCCIÓN}

"Viajar está bien. Continué viajando aún después de retirarme, no me causaba problema. El tema más importante es realmente la familia, no querer alejarme de ellos. Siento verdadera pasión por lo que hago. Si no sintiese que vale la pena tomarse el tiempo para ayudar a alguien o no tuviese una buena conexión con ellos, no es algo para lo cual me tomaría el tiempo". En este momento de mi vida, me doy el lujo de elegir y hacer lo que deseo" (Michael Chang, actual entrenador de Kei Nishikori).

Viajar es un modo de vida para muchos entrenadores, quienes apoyan y guían a sus jugadores en los lugares de entrenamiento y de torneo, lejos de casa, tanto nacional como internacionalmente. Para muchos entrenadores viajar es emocionante, divertido, estimulante y algo lleno de aventura. Ser entrenador de un circuito puede ser un trabajo soñado. Por otro lado, el viaje, para muchos entrenadores evoca una serie de sentimientos y emociones negativas como la soledad, el aburrimiento, la pena por estar lejos de los seres queridos, y una sensación de frustración ante la falta de rutina.

\section{EL ROL DEL ENTRENADOR EN EL CIRCUITO}

Los multifacéticos roles de los entrenadores están bien documentados (ej., Crespo, Reid y Quinn, 2006). Brevemente, un entrenador es alguien que planifica, guía y monitorea el desarrollo de un jugador a través de la técnica, la planificación del juego, el estado físico y la fortaleza mental (Mouratoglou,
2011). Según Patrick Mouratoglou (entrenador actual de Serena Williams), estas responsabilidades extensas se amplían aún más para el entrenador de circuito quien debe organizar el viaje, reservar las instalaciones y las canchas para el entrenamiento, seleccionar y organizar con los compañeros de práctica y entrenamiento, encordar las raquetas, gestionar la nutrición y lidiar con los patrocinadores, oficiales del torneo, y/o los medios, según sea necesario.

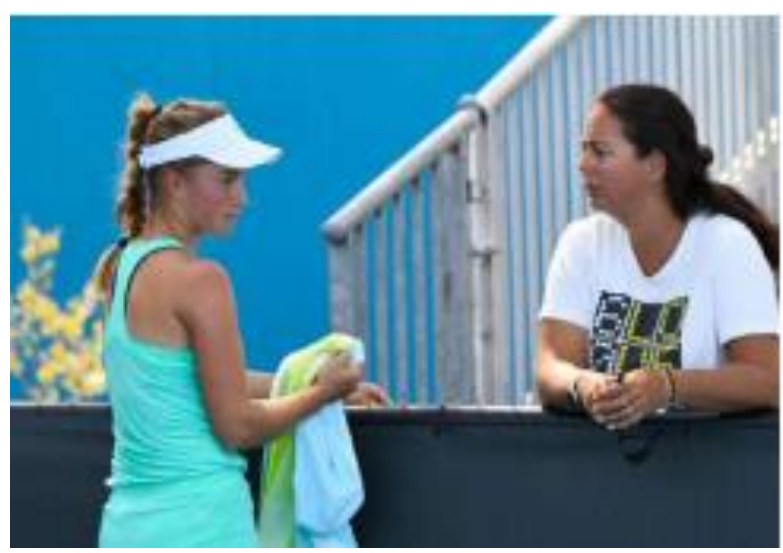

CARACTERÍSTICAS PRINCIPALES DE LA 'VIDA EN EL CIRCUITO' 
Si bien existen diferencias entre los circuitos (ej., Junior, ITF Challenger, Futures, ATP o WTA, etc.), también hay ciertos puntos comunes en la 'vida en el circuito' que se enumeran en la Tabla 1.

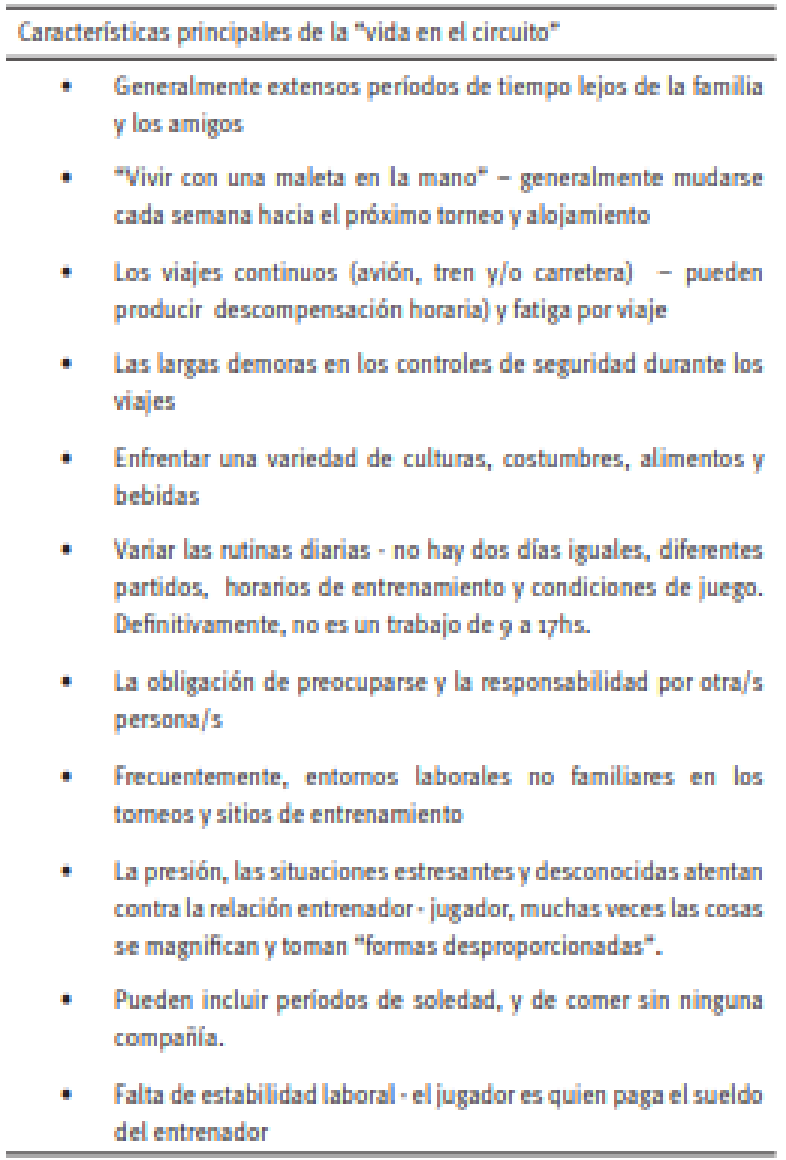

Tabla 1. Caracteristicas principales de la "vida en la circuito" para el entrenador (adaptodo de Davis (2014). Terry (2010) y Toleski (2012)].

Como se mencionó en la introducción, la 'vida en el circuito' puede ser experimentada de manera diferente por cada entrenador en particular. ¿Por qué? Se puede encontrar una explicación en el encuadre mental del individuo, con modos de pensar contrastantes, que generalmente incluyen experiencias positivas y negativas. En este contexto, la mentalidad se refiere a la perspectiva / enfoque de un individuo ante una situación o un problema.

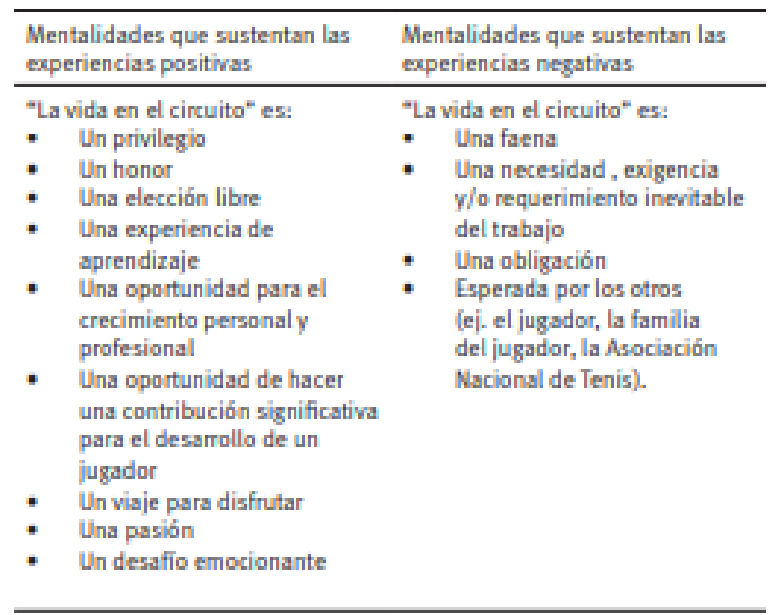

Tabla 2. Las mentalidades que narmalmente sustentan las experiencios pasitivas y negativas de "la vida en el circuito" (adaptado de Gallwey (2009) y King (2008)].

\section{RECOMENDACIONES}

Los encuadres mentales pueden desarrollarse, cambiarse y/ modificarse. Entonces, ¿qué puede hacer un entrenador para cultivar y nutrir una mentalidad que hace ver la 'vida en el circuito' de manera muy favorable? He aquí algunas sugerencias para el entrenador que desee considerar y adaptar sus necesidades y circunstancias individuales.

Tener consciencia de lo afortunado que eres de tener esta oportunidad

Ser agradecido y agradecer. No todos tienen la habilidad y el talento para ser entrenador de circuito, pero tú, sí. Perteneces a un grupo selecto y relativamente pequeño de entrenadores que viajan. Es una oportunidad que tienes ahora, y que no necesariamente se te presentará en el futuro.

Fijar metas

Gallwey (2009) recomienda fijar objetivos relacionando los tres componentes de tu trabajo, es decir, los resultados, lo que esperas aprender y el grado de disfrute que deseas en tu trabajo. Fijar objetivos específicos ayudará a aprovechar tus recursos para encontrar soluciones cuando surjan los problemas, como ocurre invariablemente en todas los torneos.

\section{Prestar atención a los detalles}

Planificar exhaustivamente los viajes para evitar sorpresas y problemas. Hacer la investigación es una tarea relativamente fácil hoy en día, con tanta información disponible en internet sobre alojamiento, transporte, clima, sedes de los torneos, alimentación, advertencias de seguridad, etc. Esta planificación proporciona una noción de control, paz y tranquilidad, por lo 
menos con respecto a jaquellos asuntos que pueden controlarse "en el circuito"!

Pedir ayuda y apoyo a un mentor o a colegas con experiencia

No todo lo debes solucionar tú. Otras personas a quienes respetes pueden ofrecerte retroalimentación y comentarios, guía e ideas sobre la mejor manera de abordar ciertos temas. Generalmente, a la hora de pedir ayuda, el primer paso es el más difícil. Te sorprenderás cuando veas cuán deseosos y contentos están los otros de poder ayudar.

\section{Observar, escuchar y aprender}

Bob Brett, Ex-Director de Desarrollo de Jugadores de la LTA, proporciona consejos sólidos sobre la oportunidad que brinda el circuito para el desarrollo profesional continuo. Su consejo es: Escuchar y observar todo lo que sucede dentro y fuera de la cancha. Ver qué hacen bien los otros. Prestar atención y ver si el conocimiento que adquieres puede transferirse a tu jugador (Davis, 2014, p.52).

\section{Focalizarse en la relación crítica entrenador-jugador}

Crear y manejar una relación entrenador-jugador saludable y respetuosa es una habilidad envidiable. Prestar atención a tu comunicación con un jugador es siempre fundamental. Toda comunicación debe ser siempre cuidadosa, oportuna y adecuada.

Buscar equilibrio en tu trabajo, familia, amigos y recreación

Deja tiempo para ti en tu agenda diaria. Para algunos entrenadores esto significa asignar tiempo al estado físico, al descanso, amigos, compras, visitas y/o a la comunicación con tus seres queridos en tu lugar de origen. No debes ignorar tus propias necesidades, pero debes ser creativo en la gestión del tiempo.

\section{Llevar diariamente un registro de "agradecimiento" o "gratitud"}

Haz una rutina diaria y anota 3-5 cosas que estuvieron (particularmente) bien para ti en ese día durante tu estancia en el torneo. Quizás desees llevar un cuaderno especial o un diario para este fin específico.

\section{Ser amable con uno mismo}

No tiene sentido auto flagelarse por los errores, faltas $u$ olvidos. Debes saber que aún los perfeccionistas no son perfectos y "la vida consta de una serie de lecciones que se deben aprender". Acepta tus imperfecciones, adáptate, si fuere necesario, y trata de encontrar lo positivo en las desilusiones, para ser un mejor entrenador y una mejor persona (King, 2008).

\section{Tener en claro "el nombre del juego"}

Algunas veces durante tu estancia debes reflexionar sobre lo que está sucediendo. ¿Estás logrando hacer diferencias con tu/s jugador/es? ¿Tu jugador entrega siempre el $100 \%$ de esfuerzo y trabaja de manera diligente todos los días, dando lo mejor de sí? Si la respuesta es "sí", entonces tanto tú como tu/s jugador/es, están jugando el juego correcto y ganando.

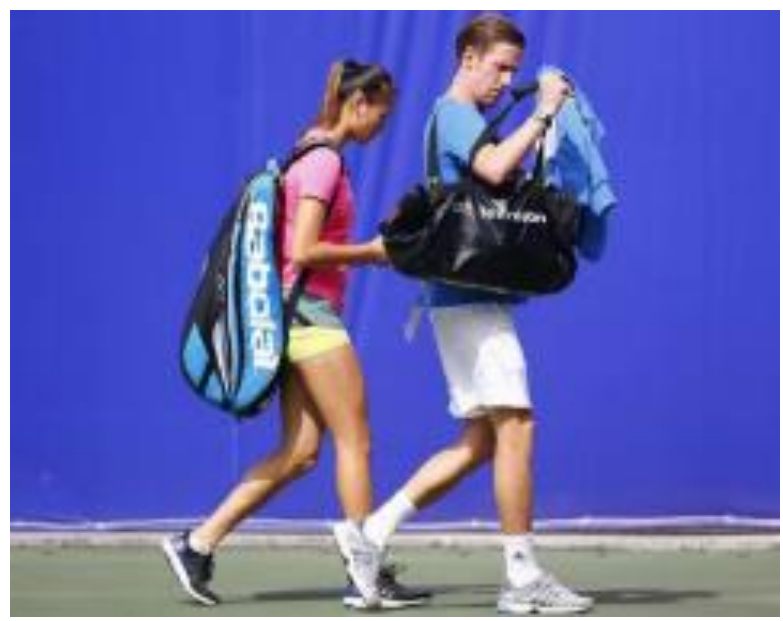

\section{CONCLUSIONES}

Este trabajo se concentra en la psicología de un entrenador de circuito. Indica que la mentalidad de un entrenador es un factor crítico para determinar cómo experimenta "la vida en el circuito". No es el único factor, pero es muy merecedor de reconocimiento, consideración y acción. Los entrenadores de circuito pueden tener un rol activo para determinar su propio destino. Primero, se requiere una consciencia del poder de la mente, y luego un deseo y un compromiso de desarrollar, cultivar y nutrir una mentalidad curiosa, creativa y reflexiva. La responsabilidad recae sobre el entrenador del circuito para hacer de su tarea el mejor trabajo soñado. Simplemente pregunta a Michael Chang, quien proporciona mucha información sobre la mente de un entrenador de campeón (ver cita inicial). La alegría del trabajo está principalmente en los ojos del espectador.

\section{REFERENCIAS}

Crespo, M., Reid, M., Quinn, A. (2006). Psicología del Tenis: 200+ practical drills and the latest research. Londres: IFT Ltd.

Davis, R. (2014). Overseeing the superstars. Australian Tennis Magazine. 39(6), 50. 
Gallwey, W.T. (2009). The Inner Game of Stress. New York: Random House.

King, B.J. (2008). Pressure is a Privilege. Lessons I've Learned from Life and the Battle of the Sexes. New York: Lifetime Media, Inc.

Mouratoglou, P. (2011). The role of the coach. Australian Tennis Magazine. 36(6), 9.

Terry, P.C. (2010). It's nice to go travelling, BUT... In S. Hanrahan \& M. Anderson (Eds.), Routledge Handbook of Applied Sport Psychology: A Comprehensive Guide for Students and Practitioners (pp. 345-354). New York: Routledge.

Toleski, D. (2012). Committing to travel. Australian Tennis Magazine, $37(7), 58-59$.

CONTENIDO ITF ACADEMY RECOMENDADO (HAZ CLICK ABAJO)

TTF Academy
Derechos de Autor (c) 2018 Janet Young

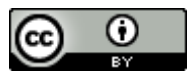

Este texto está protegido por una licencia CreativeCommons 4.0 .
Usted es libre para Compartir —copiar y redistribuir el material en cualquier medio o formato-y Adaptar el documento — remezclar, transformar y crear a partir del material- para cualquier propósito, incluso para fines comerciales, siempre que cumpla la condición de:

Atribución: Usted debe dar crédito a la obra original de manera adecuada, proporcionar un enlace a la licencia, e indicar si se han realizado cambios. Puede hacerlo en cualquier forma razonable, pero no de forma tal que sugiera que tiene el apoyo del licenciante o lo recibe por el uso que hace de la obra. 